\title{
Data Integrity
}

National Cancer Institute

\section{Source}

National Cancer Institute. Data Integrity. NCI Thesaurus. Code C142476.

The overall accuracy and consistency of information and processes for data control and use. 